\title{
La advertencia del intento persuasivo en contextos publicitarios
}

\author{
Pablo Briñol $^{1 *}$, Miguel-Ángel Cárdaba ${ }^{2}$, Ismael Gallardo 3 y Javier Horcajo ${ }^{1}$ \\ 1 Facultad de Psicología, Universidad Autónoma de Madrid, España. \\ 2 Centro Universitario Villanueva, Universidad Complutense de Madrid, España. \\ 3 Facultad de Psicología, Universidad de Talca, Chile.
}

\begin{abstract}
Resumen: Cuando las personas saben que se las está intentando convencer, tienden a resistirse puesto que en general no desean ser manipuladas. Asimismo, los mensajes ambiguos son menos persuasivos que los mensajes claros y ordenados, entre otras razones, porque las personas prefieren los estímulos fáciles de procesar. En la presente investigación se propone que estas dos variables (advertencia del intento persuasivo y ambigüedad del mensaje) pueden resultar paradójicamente más persuasivas cuando se utilizan conjuntamente. Los participantes del estudio recibieron un mensaje ordenado (baja ambigüedad) o desordenado (alta ambigüedad) que fue presentado como un anuncio publicitario (intento persuasivo) o una narración no comercial. Tal y como se esperaba, se encontró que el mensaje ambiguo resultó más persuasivo cuando fue presentado como un anuncio (contexto publicitario) que cuando fue presentado en un contexto meramente narrativo. Saber que un anuncio publicitario constituye un intento por convencer puede hacer que los pensamientos que se generen para interpretarlo sean de valencia positiva (como los argumentos que supuestamente contiene el mensaje), dando lugar a un mayor cambio de actitudes.

Palabras clave: Persuasión; actitudes; publicidad; ambigüedad; reactancia; contra-argumentar.
\end{abstract}

Title: Forewarning of the Persuasive Attempt in Advertising Contexts. Abstract: Forewarning of a persuasive attempt has been found to reduce persuasion because people tend to resist being manipulated. Likewise, messages that are high in ambiguity tend to be less persuasive than messages that are clear, among other reasons, because people prefer information that is easy to be processed. The present research postulates that these two variables (persuasive attempt forewarning and message ambiguity) can result paradoxically persuasive when combined together. Participants of the present experiment received a message composed by images that were presented in a logic (low ambiguity) or in a random order (high ambiguity). Furthermore, the message was said to be a commercial advertisement (with persuasive attempt) or a neutral narrative (without persuasive attempt). As predicted, it was found that the highly ambiguous message was more persuasive when it was presented as an advertisement (with persuasive attempt) rather than as a narrative context (without persuasive attempt). Knowing that the message constitutes a persuasive attempt (ad) could bias the generation of thoughts to interpret that information in a positive manner (consonant with the direction of the arguments supposedly contained in the ad), leading to more attitude change.

Key words: Persuasion; attitudes; advertising; ambiguity; reactance; counter-argument.

\section{Introducción}

La publicidad tiene como uno de sus objetivos primordiales crear mensajes que generen en el público actitudes más favorables hacia un producto, un servicio, una marca o una compañía. La investigación en comunicación persuasiva ha mostrado que el cambio de actitudes depende fundamentalmente de cómo el receptor interpreta y procesa la información persuasiva que recibe. En concreto, según el enfoque de la respuesta cognitiva, la persuasión aumenta a medida que el receptor genera respuestas cognitivas (i.e., pensamientos) favorables hacia la propuesta recibida, y disminuye cuando esas respuestas cognitivas generadas son desfavorables (e.g., contra-argumentaciones; Greenwald, 1968; Petty, Ostrom, y Brock, 1981).

Según el Modelo del Conocimiento de la Persuasión (Friestad y Wright, 1994; 1995) una dificultad que a menudo encuentra la publicidad es que la mayoría de las personas tiende a contra-argumentar los mensajes que reciben en la medida en que perciben que se les está intentando convencer o influir. Como resultado, las personas suelen, en general, resistirse al cambio en mayor medida ante una propuesta cuando perciben que se les quiere persuadir (Cialdini y Petty, 1981; Hass y Grady, 1975). En un estudio clásico sobre la percepción del intento persuasivo, Petty y Cacioppo (1979)

* Dirección para correspondencia [Correspondence address] Pablo Briñol. Universidad Autónoma de Madrid. Facultad de Psicología. Ciudad Universitaria de Cantoblanco, 28049 Madrid (Spain). Email: pablo.brinnol@uam.es mostraron que, cuando se advierte a los receptores de un mensaje que dicho mensaje tiene la intención de persuadirles, éstos lo contra-argumentan con mayor intensidad y, en consecuencia, demuestran una resistencia mucho mayor ante la propuesta que aquellos individuos que no son advertidos. Es decir, la advertencia del intento persuasivo puede disminuir la persuasión, en este caso sesgando el procesamiento de la información (i.e., la dirección de las respuestas cognitivas), especialmente cuando el receptor se encuentra motivado para pensar y es capaz de procesar dicha información (véase también, Boush, Friestad, y Wright, 2009).

En la literatura previa sobre los efectos de la advertencia del intento persuasivo, se han dado varias explicaciones teóricas sobre dichos efectos. Inicialmente, se consideró que la advertencia previa del intento persuasivo es interpretada por la audiencia como un intento de restringir su libertad de pensamiento, generando reactancia (Brehm, 1966), lo cual redunda en una mayor resistencia a la persuasión (Fukada, 1986). O dicho de otro modo, cuando las personas advierten que alguien quiere cambiar su manera de pensar, lo interpretan como una amenaza a su libertad y autonomía y reaccionan resistiéndose con la finalidad de recuperar o mantener su sensación de libertad (Vohs, Baumeister, y Chin, 2007). Así pues, la reactancia es un estado psicológico que puede aparecer en las situaciones en las que una persona se percibe como "objeto" o "blanco" persuasivo de alguien (para un ejemplo en el contexto comercial, véase Kirmani y Campbell, 2004).

Un segundo factor que podría ayudar a explicar la resistencia observada ante la advertencia del intento persuasivo 
guarda relación con el hecho de que las personas ven como menos creíble a un emisor que muestra su intención de convencerles (Tormala, Briñol, y Petty, 2006). Como la investigación previa ha señalado, un emisor es percibido como más creíble en la medida en que es presentado o reconocido como una fuente competente o experta respecto al objeto de actitud (Cialdini y Trost, 1998) o cuando aparece ante los ojos del receptor como una persona fiable o sincera, imparcial, e incluso capaz de argumentar en contra de sus propios intereses o, como mínimo, capaz de ocultar sus intenciones persuasivas (Walster y Festinger, 1962). Por tanto, cuando el receptor de un mensaje persuasivo percibe que el emisor tiene el interés o la intención de persuadirle, le considerará como menos creíble y, por tanto, menos convincente.

Asimismo, como se ha señalado al comienzo, el efecto negativo de la advertencia del intento persuasivo tiene especial importancia en el ámbito de la publicidad, donde la intención de convencer a los potenciales consumidores de un producto o servicio es una constante, particularmente evidente. En este sentido, el mencionado Modelo del Conocimiento de la Persuasión (Friestad y Wright, 1994; 1995) sugiere que las creencias que las personas tienen sobre el funcionamiento de la persuasión en la publicidad y en el marketing pueden jugar un papel importante en cómo esas personas responden a los intentos persuasivos. Específicamente, uno de los motivos por los cuales las personas tienden a resistirse a un mensaje publicitario es que su sola presentación en términos de publicidad comercial advierte al receptor por adelantado de que se le está intentado persuadir (e.g., Brown y Krishna, 2004; Campbell y Kirmani, 2000; Kirmani y Zhu, 2007; Quinn y Woods, 2004; Zuwerink y Devine, 1996). Esta intención persuasiva manifiesta de la publicidad contribuye a que el público, en general, desarrolle actitudes que van desde ambivalentes hasta negativas hacia la propia publicidad (e.g., considerarla como algo falso y engañoso, Calfee y Ringold, 1994). De hecho, muchas técnicas de publicidad actuales se orientan precisamente a disimular la presencia de un intento persuasivo, por ejemplo, colocando los productos dentro de escenas de películas (product placement), o utilizando formatos para el anuncio que imitan al formato empleado en documentales e informativos (publirreportajes) (e.g., Horcajo, Briñol, y Petty, 2010; Jiménez-Morales, 2005; Rucker y Tormala, 2012).

A partir de lo anterior podría concluirse que cualquier intento persuasivo que lleve asociada la etiqueta de publicidad será menos eficaz, a la hora de generar actitudes favorables hacia el producto o servicio publicitado, que ese mismo intento persuasivo en el caso de no llevar asociada dicha etiqueta. Tomadas conjuntamente, estas tres razones convergen en la idea de que un mensaje resultará menos persuasivo cuando sea etiquetado como anuncio comercial en lugar de presentado de una forma más imparcial.

Por otro lado, una variable diferente que también puede influir sobre el cambio de actitudes es la claridad y la ambigüedad del mensaje persuasivo. En general, los mensajes claros resultan más persuasivos que los mensajes poco claros o ambiguos (e.g., Hovland, Janis, y Kelley, 1953). Este efecto se puede producir por varios motivos. En primer lugar, un mensaje con alta ambigüedad podría resultar menos persuasivo que uno de menor ambigüedad debido a que, por lo general, la mayoría de las personas poseen poca tolerancia hacia la incertidumbre y reaccionan desfavorablemente ante ella (Sorrentino, Bobocel, Gitta, Olson, y Hewitt, 1988). Asimismo, los mensajes ambiguos podrían ser menos persuasivos porque son más difíciles de procesar, ya que exigen un esfuerzo mayor por parte del receptor para poder darle un sentido y una coherencia que encaje con sus expectativas. Con respecto a esto, son muchas las investigaciones que ponen de manifiesto que los mensajes o los estímulos que son fáciles de procesar son más eficaces desde el punto de vista persuasivo (Tormala, Falces, Briñol, y Petty, 2007). Así, por ejemplo, Alter y Oppenheimer (2006) encontraron que las personas valoran de un modo más positivo aquellas palabras, nombres y símbolos que son más fáciles de pronunciar. Estos mismos efectos se han observado también respecto a la calidad de la letra de un mensaje (Briñol, Petty, y Tormala, 2006), su visibilidad (Reber, Winkielman, y Schwarz, 1998) o la complejidad de su estructura sintáctica (Lowrey, 1998). Todas estas investigaciones demuestran el papel relevante de las experiencias metacognitivas en el cambio de actitud y están en consonancia con los modelos contemporáneos del juicio social (Briñol y DeMarree, 2012; Dunlosky y Metcalfe, 2009; Jost, Kruglanski, y Nelson, 1998)

Además, los mensajes ambiguos podrían ser menos persuasivos al menos por otra razón. De acuerdo con Green y Brock (2000), las narraciones poseen la capacidad de atrapar psicológicamente a los receptores y "transportarlos" al interior del mundo narrativo. Según esta perspectiva, cuando las personas son absorbidas dentro de la narración, pueden experimentar emociones y motivaciones de un modo intenso e incluso veraz, aun sabiendo que se trata de una ficción en la que los sucesos no son reales. Así, el impacto persuasivo de las narraciones -hoy en día muchos mensajes publicitarios adoptan la forma de una narración- se puede producir a través de un estado psicológico que se ha denominado transportación (Transportation). En consonancia, un mensaje se puede esperar que resulte más persuasivo en la medida en que es capaz de introducir y transportar al receptor dentro de la historia. Esta inmersión en la historia probablemente resultará más difícil en la medida en que la historia sea ambigua, desordenada, poco lógica o difícil de interpretar.

Por tanto, hasta este momento podemos concluir que tanto la advertencia de la intención persuasiva como el carácter ambiguo de un mensaje son dos factores que, al menos de forma separada, reducen la eficacia persuasiva de dicho mensaje. De todo ello, sería igualmente razonable deducir que, si un mismo mensaje incluyera las dos características (i.e., advertencia del intento persuasivo y ambigüedad), su eficacia persuasiva todavía debería ser aún menor. En este sentido, se podría predecir que el efecto negativo de las dos variables se sumaría aumentando la resistencia al cambio de actitud (efecto aditivo). 
Sin embargo, en la presente investigación se propone que la combinación de ambos factores de forma conjunta puede resultar persuasiva (efecto interactivo). Esta hipótesis se basa en la idea de que, ante un mensaje ambiguo, las personas pueden utilizar el conocimiento del intento persuasivo que acompaña a los contextos publicitarios para decidir en qué dirección procesar la información presentada. Dicho de otro modo, si no se sabe cómo interpretar un mensaje ambiguo y, sin embargo, se sabe que se trata de un anuncio comercial, es posible que las interpretaciones que surjan por parte de la audiencia se sesguen en la dirección de buscar razones positivas y favorables hacia el producto o servicio anunciado puesto que se supone que los anuncios están pensados para destacar esas cualidades buscando vender dicho producto o servicio.

Es decir, al igual que sucede en cualquier contexto comunicativo (Grice, 1975), los consumidores podrían asumir que el mensaje ofrecido por el anunciante debería ser relevante e informativo y, en consecuencia, podrían intentar generar una interpretación plausible del mismo. A su vez, como el mensaje proporcionado por el anunciante debería contener argumentos positivos o favorables hacia el producto, también deberían serlo las interpretaciones generadas por los consumidores ante un mensaje ambiguo en un contexto publicitario. De este modo, dos variables (i.e., la advertencia del intento persuasivo y la ambigüedad del mensaje), que, por separado, reducen la capacidad persuasiva de un mensaje, podrían producir actitudes más favorables cuando aparecen conjuntamente, por ejemplo, en un contexto publicitario.

Para comprobar esta hipótesis, se llevó a cabo un experimento en el que se manipularon tanto la advertencia del intento persuasivo como la ambigüedad del mensaje, y se midieron las actitudes hacia el producto. En consonancia con la argumentación previa, se esperaba que, ante un mensaje ordenado y poco ambiguo, las actitudes de los participantes que no habían sido advertidos de la intención persuasiva del mensaje fuesen significativamente más favorables que las actitudes de aquéllos que sí fueron advertidos. Sin embargo, cuando el mensaje presentado fuera desordenado y tuviera un carácter más ambiguo, esperábamos el efecto contrario. Es decir, que los participantes que fueran advertidos de la naturaleza publicitaria del mensaje manifestaran actitudes más favorables que aquéllos que no fueran advertidos.

\section{Método}

\section{Participantes}

Una muestra de 118 estudiantes (88 mujeres y 30 hombres) de la Facultad de Psicología de la Universidad Autónoma de Madrid participaron de forma voluntaria en este estudio. La media de edad fue de 21 años $(D T=2.48)$. Los participantes fueron seleccionados de acuerdo con su interés en continuar sus estudios de psicología en ámbitos relacionados con la publicidad y el marketing, para quienes el estudio probablemente resultaría de mayor relevancia personal.

\section{Diseño}

Los participantes fueron asignados de forma aleatoria a una de cuatro condiciones experimentales, según un diseño factorial inter-sujetos 2 (Advertencia del intento persuasivo: "contexto publicitario" vs. "no publicitario") X 2 (grado de ambigüedad del mensaje: "bajo" vs. "alto”).

\section{Procedimiento}

La sesión experimental fue presentada de dos formas diferentes. A la mitad de los participantes se le presentó la sesión como un estudio sobre creatividad en el contexto publicitario, mientras que para la mitad restante la sesión fue presentada como un estudio sobre creatividad en el contexto de la comprensión narrativa. La asignación de participantes a estas condiciones experimentales (contexto publicitario vs. no publicitario) fue aleatoria. Posteriormente, todos los participantes recibieron una hoja que contenía seis imágenes diferentes, donde en una de ellas aparecía una nueva marca de yogures. Para la condición de baja ambigüedad, las imágenes fueron presentadas de manera ordenada. En cambio, la otra mitad de participantes recibió las mismas imágenes desordenadas, de forma que resultase una secuencia con mayor grado de ambigüedad. La asignación de participantes a estas condiciones experimentales (baja vs. alta ambigüedad) también fue aleatoria. Finalmente, todos los participantes informaron de sus actitudes hacia el producto en una serie de ítems de diferencial semántico (variable dependiente), así como del grado de ambigüedad de la secuencia de imágenes (control de la manipulación). Al final de la sesión experimental, se explicó el objetivo de la investigación, se agradeció la participación y se solicitó el consentimiento para continuar con el análisis de los datos.

\section{Variables independientes}

Advertencia del intento persuasivo. Se varió experimentalmente la percepción que los participantes tenían sobre el contexto en que se llevaba a cabo el estudio. En concreto, se manipularon las instrucciones que los participantes recibieron antes de observar una secuencia de imágenes. Por un lado, a la mitad de los estudiantes se le dijo que iba a participar en un estudio sobre creatividad en contextos publicitarios, a partir de la observación de un anuncio de una nueva marca de yogures (condición de contexto publicitario). En cambio, a la otra mitad de participantes se le dijo que iba a participar en un estudio sobre creatividad en el contexto de la comprensión narrativa, a partir de la observación de una secuencia de imágenes (condición de contexto no publicitario). A todos ellos se les pidió que prestaran atención a la información contenida en la secuencia de imágenes puesto que, posteriormente, se les preguntarían algunas cuestiones relacionadas con la misma. 
Grado de ambigüedad. Para manipular experimentalmente la ambigüedad con que se percibían las imágenes, se varió el orden en que la secuencia mostraba dichas imágenes. A la mitad de los participantes se le presentó seis fotogramas en una secuencia lógica y ordenada (el orden original del anuncio). En este anuncio en concreto, se muestra a una niña corriendo a través de diferentes habitaciones para terminar en la cocina comiendo un yogurt. La mitad restante recibió las mismas seis imágenes, pero de manera desordenada mediante la aleatorización de las mismas. Por ejemplo, la niña aparecía comiendo el yogurt en la tercera imagen. En este caso, el objetivo era utilizar una secuencia de imágenes desordenada que generase una ambigüedad mayor que la condición en la que se presentaba de forma ordenada.

\section{Variables dependientes}

Actitudes. Para evaluar las actitudes hacia el producto, se utilizaron cuatro ítems de diferencial semántico de 9 puntos ("nada atractivo-totalmente atractivo", "desagradableagradable", "nada recomendable-muy recomendable", "totalmente en contra-totalmente a favor"). Debido a su alta correlación interna (alpha de Cronbach de .82) estos cuatro ítems fueron promediados para formar un único índice de actitudes hacia el producto. Mayores puntuaciones en este índice indicaron actitudes más positivas hacia el producto (para una medida similar de las actitudes, véase Briñol, Petty, y Stavraki, 2012; Cárdaba, Briñol, Horcajo, y Petty, 2014).

Control de manipulación. Todos los participantes contestaron en un ítem de 9 puntos al grado de ambigüedad percibido en la secuencia de imágenes ("en qué medida te ha parecido una secuencia lógica de imágenes"; desde nada lógica (1) a totalmente lógica (9). Las puntuaciones en este ítem fueron invertidas, de modo que mayores valores indicaron mayor ambigüedad.

\section{Resultados}

Actitudes. Las actitudes de los participantes fueron sometidas a un análisis de varianza (ANOVA) 2 (Advertencia del intento persuasivo: Contexto Publicitario vs. No Publicitario) X 2 (Grado de Ambigüedad: Bajo vs. Alto). Los resultados de este análisis revelaron un efecto principal significativo para el grado de ambigüedad del estímulo, $F(1,117)=10.16, p<$ .01. Como se esperaba, las actitudes de los participantes fueron más favorables hacia el producto cuando la secuencia de imágenes fue presentada de forma ordenada $(M=6.06, D T$ $=1.10)$ que cuando fue presentada de manera desordenada $(M=5.50, D T=1.00)$. En cambio, no se encontró un efecto principal significativo de la variable advertencia del intento persuasivo $(F<1)$.

Lo más importante para los objetivos de la presente investigación fue que, tal y como se pronosticó, el efecto principal de la ambigüedad del mensaje fue cualificado por un efecto significativo de la interacción entre la advertencia del intento persuasivo y el grado de ambigüedad, sobre las acti- tudes, $F(1,116)=8.04, p<.01$. Esta interacción indicó que, cuando la secuencia de imágenes fue ordenada (i.e., condición de baja ambigüedad), las personas evaluaron de manera más favorable el producto en el contexto no publicitario $(M$ $=6.37, D T=1.17)$ que en el publicitario $(M=5.81, D T=$ $1.11, F(1,116)=4.23, p<.05)$. Sin embargo, para el grupo que recibió la secuencia de imágenes de manera desordenada (i.e., condición de alta ambigüedad), como se esperaba, el efecto fue el opuesto. Es decir, las actitudes hacia el producto fueron más favorables cuando el contexto fue publicitario $(M=5.73, D T=0.93)$ que cuando el contexto fue no publicitario $(M=5.13, D T=1.07), F(1,116)=3.85, p=.05$.

Control de manipulación. Tal y como se esperaba, los resultados del análisis de varianza (ANOVA) 2 (Advertencia del intento persuasivo: Contexto Publicitario vs. No Publicitario) X 2 (Grado de Ambigüedad: Bajo vs. Alto) sobre el control de la manipulación del grado de ambigüedad sólo revelaron un efecto principal significativo del grado de ambigüedad sobre la percepción de la ambigüedad de la secuencia, $F$ $(1,116)=59.78, p<.01$. En concreto, los participantes que recibieron la secuencia de imágenes desordenada percibieron dicha secuencia como más ambigua $(M=6.78 ; D T=2.03)$ que los participantes que recibieron la secuencia de imágenes ordenada $(M=3.57 ; D T=2.39)$.

\section{Discusión}

Los resultados de la presente investigación replican los encontrados en investigaciones previas tanto para la advertencia del intento persuasivo como para la ambigüedad de los mensajes. Por un lado, la advertencia del intento persuasivo redujo la persuasión en condiciones de baja ambigüedad. Este resultado replica la investigación previa mostrando que un mensaje resulta menos persuasivo si se da a conocer explícitamente como un anuncio comercial (e.g., Friestad y Wright, 1994; 1995; Quinn y Wood, 2004). Además, este resultado es compatible con los modelos teóricos que defienden que las personas se resisten a ser manipuladas (Boush et al., 2009). Por otro lado, los mensajes de mayor ambigüedad resultaron menos persuasivos que los mensajes de menor ambigüedad. Este resultado también está en línea con la investigación previa que demuestra que las personas evalúan más favorablemente los mensajes que son más ordenados y fáciles de procesar (e.g., Alter y Oppenheimer, 2006; Briñol et al., 2006). Por tanto, los resultados obtenidos son compatibles con los modelos actuales basados en el papel que juega la metacognición en el juicio social (Briñol y DeMarree, 2012). Ambos resultados confirman que estas dos variables (advertencia del intento persuasivo y ambigüedad) resultan contraproducentes.

Ahora bien, el resultado más importante del presente estudio es que estas dos variables que reducen la persuasión tomadas de forma aislada pueden resultar especialmente persuasivas cuando se combinan simultáneamente. Tal y como esperábamos, dos variables que incrementan la resistencia al cambio pueden generar un efecto persuasivo paradójico al 
actuar conjuntamente. De acuerdo con nuestra hipótesis, cuando no se entiende un mensaje, el contexto en el que se presenta dicho mensaje puede ayudar a darle sentido, al menos a saber en qué dirección interpretarlo. Los datos del estudio fueron consistentes con esta posibilidad. Cuando el mensaje se presentó de forma desordenada y fue percibido como poco lógico, resultó más persuasivo al ser presentado como un anuncio (contexto publicitario) que cuando fue presentado en un contexto meramente narrativo o no publicitario. Puede interpretarse, por tanto, que saber que un mensaje constituye un anuncio (i.e., un intento por convencer) puede provocar que los pensamientos que generemos para interpretarlo sean de valencia positiva. Es decir, ante un mensaje que era poco comprensible, los participantes del estudio posiblemente generaron pensamientos favorables de lo que debía de querer decir el mensaje al saber que se trataba de un anuncio. Dicho de otra forma, si no sabemos nada del producto (los nuevos yogures), al saber que nos los están intentando vender, probablemente esto lleve a pensar en los posibles argumentos favorables que puede haber detrás del anuncio. Futuros trabajos deberán incluir un registro sistemático de estas interpretaciones para confirmar su papel en la explicación de los presentes resultados.

Asimismo, es importante señalar que, si el mecanismo que hay detrás de este efecto es, como planteamos, de naturaleza deliberativa, dicho efecto debería producirse solamente cuando las personas estén motivadas y tengan la capacidad necesaria para pensar (Petty y Cacioppo, 1986; Petty y Briñol, 2012). En caso contrario, cuando las personas no tienen capacidad ni motivación para procesar sistemáticamente el contenido del mensaje, sería razonable suponer un resultado doblemente negativo puesto que los receptores se enfrentarían a un mensaje que no sólo saben que está diseñado para persuadirles, sino que además es difícil de entender. En el caso de personas que no procesan la información detenidamente, tanto la advertencia del contexto persuasivo como la ambigüedad serían dos variables que, previsiblemente, funcionarían como claves periféricas para posicionarse en contra del anuncio y/o el producto de una forma aditiva. En este trabajo las condiciones de elaboración fueron relativamente altas, tanto por la motivación de la muestra como por las instrucciones explícitas de prestar atención que recibieron los participantes. Futuros trabajos deberán manipular la probabilidad de elaboración como un factor que puede moderar cuándo estas dos variables dan lugar a actitudes favorables (e.g., en condiciones de alta elaboración) o desfavorables (e.g., en condiciones de baja elaboración). Descrita de otra forma, esta interpretación hace referencia a la posibilidad de

\section{Referencias}

Alter, A. L., y Oppenheimer, D. M. (2006). Predicting short-term stock fluctuations by using processing fluency. Proceedings of the National Academy of Sciences, 103, 9369-9372.

Boush, D. M., Friestad, M., y Wright, P. (2009). Deception in the marketplace. New York, NY: Routledge. que combinar estas dos variables en otras circunstancias de elaboración podría dar lugar a resultados opuestos (efecto negativo aditivo) si esas condiciones varían el proceso psicológico subyacente.

Otra vía para una futura investigación tiene que ver con la credibilidad de la fuente (Tormala et al., 2006). En principio, se puede especular que la competencia del emisor del mensaje podría ser otro posible moderador del efecto encontrado en esta investigación. El efecto encontrado es más probable que ocurra cuando los receptores de un mensaje ambiguo presupongan que el emisor es competente y que, por tanto, debe estar proponiendo argumentaciones fuertes y favorables hacia el producto. Si la audiencia pensara que el emisor no es competente, simplemente podrían pensar que el anuncio es malo o está mal construido y no buscar interpretaciones positivas ante la ambigüedad.

Asimismo, los resultados obtenidos en la presente investigación no sólo tienen implicaciones para contextos estrictamente publicitarios o comerciales, sino que también se pueden aplicar a otros dominios en los que se presuponga una intención persuasiva y en el que los receptores compartan unos mismos supuestos sobre el funcionamiento de las comunicaciones persuasivas. Por ejemplo, instruir o predicar mediante parábolas difíciles de descifrar en contextos educativos y religiosos podría ser una estrategia especialmente eficaz con aquellas personas motivadas y con capacidad para pensar sobre el significado (supuestamente instructivo) que debería esconderse detrás de esas enigmáticas palabras. Lo mismo podría suceder en otros contextos persuasivos explícitos como son, por ejemplo, las entrevistas de trabajo o las interacciones personales cuya finalidad sea seducir o cortejar a la otra parte. Si se sabe que alguien se está intentando vender y no se entiende el mensaje que entrega, probablemente las interpretaciones que se generen sean de valencia positiva.

En conclusión, el presente trabajo de investigación muestra cómo dos variables que reducen la persuasión cuando están presentes de forma separada, al unirse en un mismo tratamiento persuasivo consiguen aumentar el cambio de actitudes en la audiencia. Como se ha señalado, las futuras investigaciones deberán explorar con mayor precisión los mecanismos psicológicos subyacentes a los efectos aquí encontrados, así como estudiar las potenciales variables moderadoras de estos efectos.

Agradecimientos.- El presente trabajo ha sido parcialmente financiado por el MICINN (PSI2011-26212). También extendemos nuestra gratitud a Irene Díaz Rodríguez por su ayuda en la recogida de datos.

Brehm, J. W. (1966). A theory of psychological reactance. San Diego, CA: Academic Press.

Briñol, P., y DeMarree, K. G. (Eds.). (2012). Social metacognition. New York, NY: Psychology Press.

Briñol, P., Petty, R. E., y Stavraki, M. (2012). Power increases the reliance on first-impression thoughts. Revista de Psicología Social, 27, 293-303. 
Briñol, P., Petty, R. E., y Tormala, Z. L. (2006). The meaning of ease and its malleability. Psychological Science, 17, 200-206.

Brown, C. L., y Krishna, A. (2004). The skeptical shopper: A metacognitive account for the effects of default options on choice. Journal of Consumer Research, 31, 529-539.

Calfee, J. E., y Ringold, D. J. (1994). The 70\% majority: Enduring consumer beliefs about advertising. Journal of Public Policy and Marketing, 13, 228238.

Campbell, M. C., y Kirmani, A. (2000). Consumers' use of persuasion knowledge: The effects of accessibility and cognitive capacity on perceptions of an influence agent. Journal of Consumer Research, 27, 69-83.

Cárdaba, M. A. M., Briñol, P., Horcajo, J., y Petty, R. E. (2014). Changing prejudiced attitudes by thinking about persuasive messages: Implications for resistance. Journal of Applied Social Psychohogy, 44, 343-353.

Cialdini, R. B., y Petty, R. E. (1981). Anticipatory opinion effects. En R. E. Petty, T. M. Ostrom, y T. C. Brock (Eds.), Cognitive responses in persuasion (217-235). Hillsdale, New Jersey: Erlbaum.

Cialdini, R. B., y Trost, M. R. (1998). Social influence: Social norms, conformity, and compliance. En D. Gilbert, S. Fiske, y G. Lindzey (Eds.), The handbook of social psychology, (4th ed., pp. 151-192). New York: McGraw-Hill.

Dunlosky, J., y Metcalfe, J. (2009). Metacognition. Thousand Oaks, CA: Sage.

Friestad, M., y Wright, P. (1994). The persuasion knowledge model: How people cope with persuasion attempts. Journal of Consumer Research, 21, 131

Friestad, M., y Wright, P. (1995). Persuasion knowledge: Lay people's and researches' beliefs about the psychology of persuasion. Journal of Consumer Research, 22, 123-156.

Fukada, H. (1986). Psychological processes mediating the persuasion inhibiting effect or forewarning in fear arousing communication, Psychological Reports, 58, 87-90.

Green, M. C., y Brock, T. C. (2000). The role of transportation in the persuasiveness of public narratives. Journal of Personality and Social Psychology, 79, 701-721.

Greenwald, A. G. (1968). Cognitive learning, cognitive response to persuasion, and attitude change. En A. G. Greenwald, T. C. Brock y T. M. Ostrom (Eds), Psychological foundations of attitudes. New York: Academic Press.

Grice, H. P. (1975). Logic and conversation. En P. Cole y J. L. Morgan (Eds.), Syntax and Semantics III: Speech Acts (pp. 41-58). New York: Academic Press.

Hass, R. G., y Grady, K. (1975). Temporal delay, type of forewarning, and resistance to influence. Journal of Experimental Social Psychology, 11, 459-469.

Horcajo, J., Briñol, P., y Petty, R. E. (2010). Consumer persuasion: Indirect change and implicit balance. Psychology \& Marketing, 27, 938-963.

Hovland, C. I., Janis, I. L., y Kelley, H. H. (1953). Communication and persuasion: Psychological studies of opinion change. New Haven, CT: Yale University Press.

Jiménez-Morales, M. (2005). "Selling me softly, la persuasión sutil": Influencia del product placement en las audiencias infantiles de las teleseries. Comunicar, 25.

Jost, J. T., Kruglanski, A. W., y Nelson, T. O. (1998). Social metacognition: An expansionist review. Personality and Social Psychology Review, 2, 137-
Kirmani, A., y Campbell, M. C. (2004). Goal seeker and persuasion sentry: How consumer targets respond to interpersonal marketing persuasion. Journal of Consumer Research, 31, 573-582.

Kirmani, A., y Zhu, R. (2007). Vigilant against manipulation: The effects of regulatory focus on the use of persuasion knowledge. Journal of Marketing Research, 44, 688-701.

Lowrey, T. M. (1998). The effects of syntactic complexity on advertising persuasiveness. Journal of Consumer Psychology, 7, 187-206.

Petty, R. E., y Briñol, P. (2012). The Elaboration Likelihood Model. En P. A. M. Van Lange, A. Kruglanski, y E. T. Higgins (Eds.), Handbook of theories of social psychology (Vol.1, pp. 224-245). London, England: Sage.

Petty, R. E., y Cacioppo, J. T. (1979). Effects of forewarning of persuasive intent on cognitive responses and persuasion. Personality and Social Psychology Bulletin, 5, 173-176.

Petty, R. E., y Cacioppo, J. T. (1986). The Elaboration Likelihood Model of Persuasion. En L. Berkowitz (Ed.), Advances in experimental social psychology (Vol. 19, pp. 123-205). New York: Academic Press.

Petty, R. E., Ostrom, T. M., y Brock, T. C. (Eds.) (1981). Cognitive responses in persuasion. Hillsdale, New Jersey: Erlbaum.

Quinn, J. M., y Wood, W. (2004). Forewarnings of influence appeals: Inducing resistance and acceptance. En E. S. Knowles y J. A. Linn (Eds.), Resistance and Persuasion (pp.193-213). Mahwah, New Jersey: Lawrence Erlbaum Associates.

Reber, R., Winkielman, P., y Schwarz, N. (1998). Effects of perceptual fluency on affective judgments. Psychological Science, 9, 45-48

Rucker, D. D., y Tormala, Z. L. (2012). Metacognitive theory in consumer research. En P. Briñol y K. G. DeMarree (Eds.), Social Metacognition (pp. 303-321). New York, NY: Psychology Press.

Sorrentino, R. M., Bobocel, C. R., Gitta, M. Z., Olson, J. M., y Hewitt, E. C. (1988). Uncertainty orientation and persuasion: Individual differences in the effects of personal relevance on social judgments. Journal of Personality and Social Psychology, 55, 357-371

Tormala, Z. L., Briñol, P., y Petty, R. E. (2006). When credibility attacks: The reverse impact of source credibility on persuasion. Journal of Experimental Social Psychology, 42, 684-691.

Tormala, Z. L., Falces, C., Briñol, P., y Petty, R. E. (2007). Ease of retrieval effects in social judgment: The role of unrequested cognitions. Journal of Personality and Social Psychology, 93, 143-157

Vohs, K. D., Baumeister, R. F., y Chin, J. (2007). Feeling duped: Emotional, motivational, and cognitive aspects of being exploited by others. Review of General Psychology, 11,127-141.

Walster, E., y Festinger, L. (1962). The effectiveness of 'overheard' persuasive communications. Journal of Abnormal and Social Psychology, 65, 395-402.

Zuwerink, J. R., y Devine, P. G. (1996). Attitude strength and resistance to persuasion: It's more than just the thought that counts. Journal of Personality and Social Psychology, 70, 931-944.

(Artículo recibido: 17-9-2012; revisado: 29-4-2013; aceptado: 20-5-2013) 